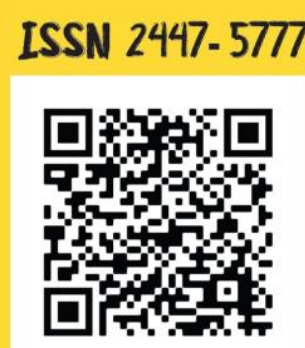

E

M

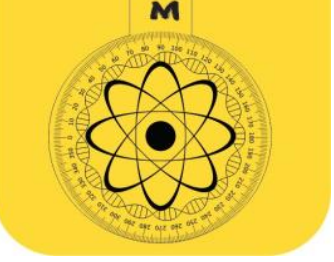

MULTIDISCIPLINARIDADE

Jul. | Dez. 2021 - Volume 7, Número 2, p. 13-24.

\title{
Joaquim de Oliveira Santos e a modernização da aritmética da escola primária ludovicense
}

\author{
Joaquim de Oliveira Santos and the modernization of arithmetic in the \\ Ludovician primary school
}

\author{
Maria do Carmo Alves da Cruz ${ }^{1}$ - https://orcid.org/0000-0002-7928-1284 \\ Neuza Bertoni Pinto ${ }^{2}$ - https://orcid.org/0000-0002-9224-3020
}
${ }^{1}$ Mestra em Educação pela Universidade Federal do Maranhão (UFMA). Professora do Curso de Licenciatura em Pedagogia na Universidade Federal do Maranhão (UFMA), São Luís, Maranhão, Brasil. E-mail: docarmo_cruz@hotmail.com
${ }^{2}$ Doutora em Educação pela Universidade de São Paulo (USP). Professora Colaboradora do Programa de Pós- Graduação em Educação em Ciências e Matemática - PPGECEM- REAMEC - (UFMT), Curitiba, Paraná, Brasil. E-mail: neuzabertonip@gmail.com

\begin{abstract}
Resumo
Este estudo tem como objetivo compreender as contribuições do professor Joaquim de Oliveira Santos na modernização da Aritmética da Escola Primária ludovicense. O texto busca responder ao questionamento central: quais as contribuições de Joaquim de Oliveira Santos na modernização da aritmética da escola primária ludovicense? Para tanto, vale-se do aporte teórico-metodológico ancorado na História Cultural, com base nos trabalhos de Chartier (2017), e na História da educação matemática, com base em Valente (2017) e Pinto (2017). Quanto ao corpus investigativo, as fontes incluem documentos oficiais e, principalmente, livros didáticos escritos pelo professor. A produção do professor Joaquim de Oliveira Santos, identificada nos documentos aos quais tivemos acesso, evidencia incessante busca pela modernização da Aritmética da escola primária ludovicense, bem como pela melhor qualidade da formação de professores primários maranhenses em tempos da vaga intuitiva. As análises permitem inferir que o professor Joaquim de Oliveira Santos desenvolveu trabalhos com vistas à modernização da Aritmética do ensino primário em São Luís, em harmonia com aquilo que era evidenciado no cenário educacional em níveis nacional e internacional.
\end{abstract}

Palavras-chave: Joaquim de Oliveira Santos. Ensino de matemática. Escola Primária. História da Educação do Maranhão.

\begin{tabular}{|c|c|}
\hline \multicolumn{2}{|c|}{ Abstract } \\
\hline $\begin{array}{l}\text { nis study } \\
\text { rithmetic }\end{array}$ & $\begin{array}{l}\text { o understand the contributions of Professor Joaquim de Oliveira Santos in the modernization } \\
\text { cola Primária Ludovicense. The text seeks to answer the central question: what are }\end{array}$ \\
\hline $\begin{array}{l}\text { Como cita } \\
\text { escola prim }\end{array}$ & $\begin{array}{l}\text { CRUZ, M. C. A.; PINTO, N. B. Joaquim de Oliveira Santos e a modernização da aritmética da } \\
\text { a ludovicense. Ensino \& Multidisciplinaridade, São Luís (MA), v. 7, n. 2, p. 13-24, } 2021 .\end{array}$ \\
\hline (cc) & $\begin{array}{l}\text { Este é um artigo publicado em acesso aberto (Open Access) sob a licença Creative Commons Attribution, que permite uso, } \\
\text { distribuição e reprodução em qualquer meio, sem restrições desde que o trabalho original seja corretamente citado. }\end{array}$ \\
\hline
\end{tabular}


contributions of Joaquim de Oliveira Santos in the modernization of Arithmetic at Elementary School Ludovicense? For that, it makes use of the theoretical-methodological contribution anchored in Cultural History, based on the works of Chartier (2017), the History of Mathematics Education, Valente (2017), Pinto (2017). As for the investigative corpus, the sources include official documents, and mainly textbooks written by the professor. The production of teacher Joaquim de Oliveira Santos, identified in the documents to which we had access, shows the teacher's incessant search for the modernization of Arithmetic in the ludovician Elementary School, as well as for the better quality of education for primary teachers in Maranhão, in times of the intuitive wave. The analyzes allow us to infer that Professor Joaquim de Oliveira Santos developed works with a view to modernizing Arithmetic in primary education in São Luís, in harmony with what was evident in the educational scenario at national and international levels.

Keywords: Joaquim de Oliveira Santos. Teaching math. Primary School. History of Education in Maranhão.

\section{Introdução}

Este trabalho é um recorte de uma pesquisa de doutorado em andamento no Programa de Pós-Graduação em Educação em Ciências e Matemática - PPGECEM-UFMT, da Rede Amazônica de Educação em Ciências e Matemática - REAMEC. Neste texto, tentamos compreender as contribuições do professor Joaquim de Oliveira Santos para a modernização do ensino de matemática na escola primária ludovicense.

Nesse sentido, a pesquisa tenta responder à pergunta: quais as contribuições de Joaquim de Oliveira Santos na modernização da aritmética da escola primária ludovicense? Para contemplá-la, buscamos suporte em diferentes jornais da época, a saber: Diário do Maranhão e Pacotilha; um integrou a imprensa oficial e o outro foi oposição ao governo da época, respectivamente. Ademais, documentos oficiais, como "A Mensagem do Governador ao Congresso", de 1922, e documentos escolares, como a revista pedagógica A Escola, foram elencados como fontes, uma vez que estabelecemos o critério de que deveriam conter informações sobre o referido professor. ${ }^{1}$

Em se tratando dos aspectos teórico-metodológicos, ancorados na História Cultural, baseamo-nos na ideia de Roger Chartier, principalmente por entender a existência

[...] indissociável do global e do local que levou alguns a propor a noção de " glocal', que designa com correção, os processos [...] as referências partilhadas, os modos impostos, os textos e os bens que circulam mundialmente, para fazer sentido em um tempo e em um lugar concreto (CHARTIER, 2017, p. 57).

Compreendemos que a atuação do professor Joaquim de Oliveira Santos, no Maranhão, mantinha estreito diálogo com as transformações nos cenários educacionais em níveis nacional e internacional.

Ainda sobre aspectos teórico-metodológicos estamos trabalhando com o conceito de apropriação de Roger Chartier, para quem a apropriação "[...] visa a elaboração de uma história social dos usos e das interpretações, relacionados às suas determinações fundamentais e inscritos nas práticas específicas que os constroem" (CHARTIER, 1995, p. 184). Para o pesquisador, a leitura e a interpretação promovem um processo de apropriação das práticas de cada grupo, a partir de textos, de códigos, de modelos compartilhados.

Para as análises das fontes, fizemos imersões, que conforme a ótica de Castro (2017), ora são rasas, ora mais profundas. Uma imersão de múltiplos poderes que os arquivos possuem, o que possibilitou uma operação técnica de separar, agrupar e transformar documentos, dando-

\footnotetext{
${ }^{1}$ Ressaltamos que todos os arquivos que compõem o corpus estão disponíveis de forma digital nos sítios da Biblioteca Pública Benedito Leite, do Arquivo Público do Maranhão, bem como da Casa de Cultura Josué Montelo.
} 
lhes um novo aspecto pela transcrição, pela fotografia, mudando sua feição, lugar, tempo e estatuto (DE CERTEAU, 1982).

Portanto, no tocante à estruturação deste trabalho, após esta breve introdução, apresentamos a trajetória profissional de Joaquim de Oliveira Santos, desde o início de seus estudos, enfatizando os cargos, os conflitos, sobretudo, suas exímias contribuições na modernização da matemática na escola primária ludovicense, em seguida as considerações finais que objetivam sintetizar o estudo ora apresentado.

\section{Um professor múltiplo em diversos espaços}

Joaquim de Oliveira Santos nasceu no dia 17 de fevereiro de 1871, na cidade de Rosário, a 70 km da capital São Luís, e faleceu em 24 de setembro de 1930, na capital maranhense. Filho de Joaquim José dos Santos e Luzia de Oliveira Santos, sua trajetória escolar iniciou no antigo Seminário das Mercês ${ }^{2}$, em seguida, cursou humanidades, no Liceu Maranhense. Iniciou sua carreira docente como professor de Aritmética, Álgebra e Geometria, na Escola Normal, tendo se aposentado durante o governo de Godofredo Vianna (1922 a 1925).

As contribuições do professor Joaquim de Oliveira Santos, para a formação do professor que ensina matemática nos primeiros anos escolares, estão no contexto de uma transição secular em terras maranhenses; ele foi um grande entusiasta do ensino intuitivo. Tal fato, ganhou maior visibilidade nos anos de 1908 e 1909, quando a Lei estadual n.475, de 21 de março de 1908, estabeleceu a adoção dos seus livros, dentre eles: "Moderna Tabuada ou Primeiros Exercícios de Ginástica com os números", em toda Instrução Primária maranhense. Esse documento oficial atesta o reconhecimento do Estado pela produção científica de Joaquim de Oliveira Santos.

Conforme noticiou o Jornal Diário do Maranhão (1911, p.1), durante as atividades como docente, o então Inspetor Geral da Instrução Pública no Maranhão, Antônio Lobo, quando questionado pelo diretor da Escola Normal Maranhense sobre o porquê da utilização dos livros Primeiros Passos em Álgebra, de autoria de Wallace C. Boyden (Figura 1), escrito em espanhol, e Concrete Geometry, de Adelia R. Hornbrook (Figura 2), em inglês, respondeu que consultou professores de respeitáveis conhecimentos, e competência na matéria, com absoluta probidade profissional reconhecida pelos professores maranhenses, Joaquim de Oliveira Santos foi um dos professores consultados.

Os dois livros já tinham sido adotados na Escola Normal, em 1908, pelo professor Joaquim de Oliveira Santos. Em artigos publicados no jornal, Antônio Lobo relata que naquele período o uso dos compêndios contribuiu para que diversos alunos da Escola Normal sustentassem com vantagem, a prova pública da habilitação em Álgebra e Geometria, e duas alunas foram as primeiras a receber o grau de professoras laureadas (DIÁRIO DO MARANHÃO, 1911).

\footnotetext{
${ }^{2}$ Construção datada de 1654, inaugurada pelo pe. Antônio Vieira, tombado como Patrimônio Histórico Nacional, inicialmente Convento da Ordem dos Mercedários, após ter abrigado várias organizações como a Polícia, desde 2011, abriga a Fundação da Memória Republicana Brasileira.
} 


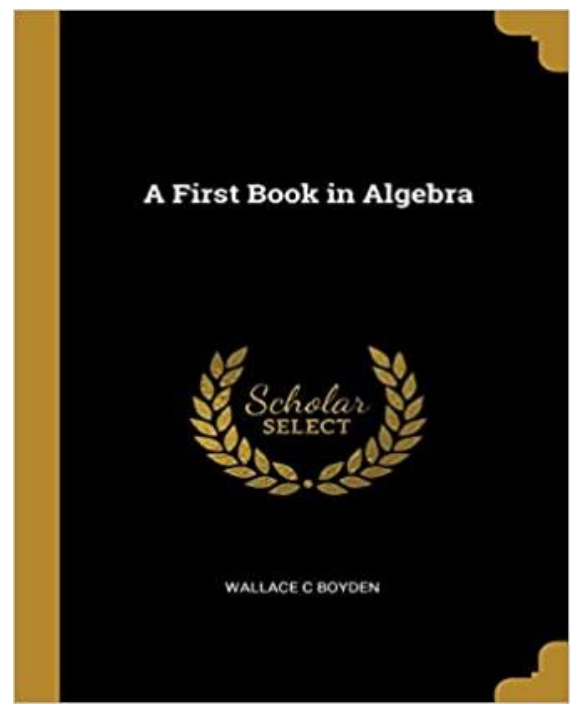

Figura 1 - Capa do livro Primeiros Passos em Álgebra

Fonte: Geometria concreta para iniciantes por Adelia R. Hornbrook (1895)

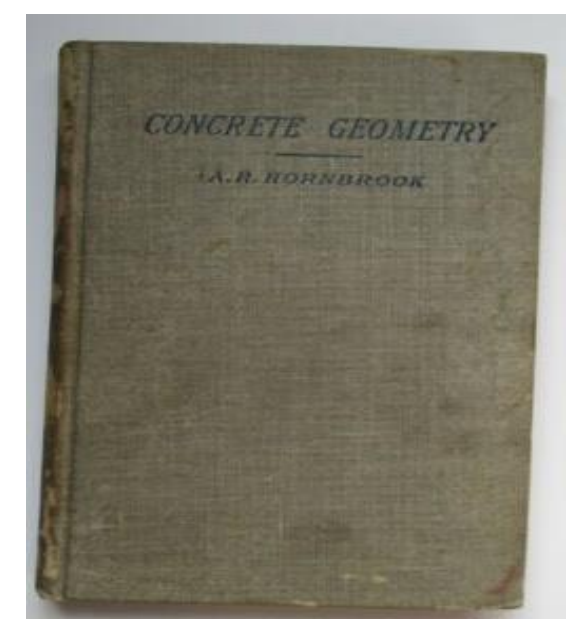

Figura 2 - Capa do livro Concrete Geometry

Fonte: Geometria concreta para iniciantes por Adelia R. Hornbrook (1895)

Joaquim Santos respondeu em carta pública as razões e os resultados em utilizar as obras, além de fazer uma análise de ambas. Para o professor Primeiros Passos em Álgebra é um excelente livro de texto que, apesar de estar escrito em espanhol,

Os principiantes entendem muito regularmente e não encontram dificuldades na compreensão dos conceitos, fato recorrente em alguns compêndios escritos em Língua Portuguesa. Enquanto Concrete Geometry é destacado por ser o único (e ainda hoje ninguém apresentou melhor), que mais se aproxima dos intuitos do ensino da forma numa Escola Normal (DIÁRIO DO MARANHÃO, 1911, p. 1).

Os dois livros já tinham sido adotados na Escola Normal, em 1908, pelo professor Joaquim de Oliveira Santos. Em artigos publicados no jornal, Antônio Lobo relata que naquele período o uso dos compêndios contribuiu para que diversos alunos da Escola Normal sustentassem com vantagem, a prova pública da habilitação em Álgebra e Geometria, e duas 
alunas foram as primeiras a receber o grau de professoras laureadas (DIÁRIO DO MARANHÃO, 1911).

Joaquim Santos respondeu em carta pública as razões e os resultados em utilizar as obras, além de fazer uma análise de ambas. Para o professor Primeiros Passos em Álgebra é um excelente livro de texto que, apesar de estar escrito em espanhol,

Os principiantes entendem muito regularmente e não encontram dificuldades na compreensão dos conceitos, fato recorrente em alguns compêndios escritos em Língua Portuguesa. Enquanto Concrete Geometry é destacado por ser o único (e ainda hoje ninguém apresentou melhor), que mais se aproxima dos intuitos do ensino da forma numa Escola Normal (DIÁRIO DO MARANHÃO, 1911, p. 1).

O professor aponta ainda quatro motivos para a escolha destes títulos:

$1^{\circ}$ ser de necessidade imperiosa de terem os alunos um livro texto: pois, do contrário, o curso se atrasa; é difícil esgotar-se o programa no ano letivo com proveito; os alunos são obrigados a tomar muitos apontamentos nas aulas, os quais, por sinal, são um trabalho quase sempre mal feito, incompleto e confuso; $2^{\circ}$ adotar livros textos de Álgebra e Geometria apropriados para um curso da Escola Normal, em que o ensino deve seguir a norma a que mais tarde o normalista também deve obedecer no ensino à criança; $3^{\circ}$ a convicção que sempre tive de um curso de Matemática para uma Escola Normal, não se trata de ensinar muito, e sim o suficiente, mas bom, não posso entregar aos meus alunos um livro que não estivesse de acordo com o meu modo de entender; $4^{\circ}$ os alunos de Álgebra, com poucas exceções, já terem estudado o $1^{\circ}$ e o $2^{\circ}$ ano de Aritmética; e os alunos de Geometria, ao menos, dois anos de inglês nesta mesma instituição (DIÁRIO DO MARANHÃO, 1911, p. 1).

Joaquim de Oliveira Santos, ao defender os livros afirma saber o que há de bom para se emancipar desse ensino clássico da Matemática elementar, o qual, por sua vez, tem contribuído para o juízo errôneo que tem corrido mundo - de ser a Matemática a ciência mais difícil, quando a verdade é exatamente o contrário, ela é a mais simples das ciências e por isso mesmo é a que com mais facilidade se pode aprender (SANTOS, 1911).

Ao analisar os dois livros, o professor afirma que na obra Os Primeiros Passos em Álgebra: o autor não começa com definições, nem generalização sem sentido para o estudante; mas guia-o pela mão através de uma interessante série de problemas muito bem graduados. Em seguida, nas ideias preliminares, utiliza de exemplos, ao contrário do que comumente se pratica, fazendo uso de seis operações de um modo prático mais inteligente em que é abundante de muitos e variados exercícios (Ibidem).

Na seção posterior, de acordo com o professor, o livro orienta a prática do mecanismo algébrico, desse modo, essa seria uma parte básica para que o estudante pudesse deslindar os segredos das transformações algébricas. E, então, passar a resolução das equações do $1^{\circ}$ grau, aliás já delineada no princípio com a resolução dos problemas, e termina essa parte com a resolução da equação do $2^{\circ}$ grau, teoria que não completa, porque o livro só se destina ao iniciante. $\mathrm{O}$ final do livro é composto de lista de soluções das questões propostas para conferir as resoluções; para Joaquim Santos, trabalhar com esse livro é ter certeza de ter bons resultados.

O professor Santos relata, ainda, que quando mostrou o livro para seu antigo professor de Matemática no Liceu Maranhense, Dr. Raimundo Honório da Silva, que naquele momento era professor de Geometria na Escola Normal de Pernambuco, profissional reconhecido nacionalmente sobre o ensino da Matemática elementar; Santos afirma que o docente gostou tanto do livro que decidiu levá-lo para Recife e disse a Joaquim que pedisse outro para ele.

Inicialmente, Santos tece críticas a alguns compêndios de geometrias, para quem não se pode ignorar que os compêndios de geometria não são livros de texto e, além disso, são 
difíceis para o estudante, mesmo possuidor de regular preparo de álgebra; porque eles, de princípio ao fim, consistem numa sobrecarga de demonstrações de teoremas, dos quais não trazem aplicações a questões comuns. Exigem, por conseguinte, que o estudante possua linguagem própria e, acima de tudo, saiba encadear as diversas proposições de que constar o raciocínio (SANTOS, 1911).

Embora fosse um bom exercício de disciplina mental para quem o soubesse aproveitar, Santos diz ser, todavia, um trabalho sem resultado prático para um aluno que se destina a ser professor normalista, pois não terá a finalidade de ensinar demonstrações clássicas às crianças, também não deverá limitar o ensino da forma a simples terminologia geométrica; terá de fazer um ensino prático, mas inteligente, e útil (SANTOS, 1911).

Preenche tais fins a Geometria Concreta de Adélia R. Hornbrook, que não é uma Geometria que se ocupa exclusivamente em demonstrar teoremas, mas leva a conclusão daqueles de que trará, por meio de uma série de quesitos logicamente subordinados uns aos outros, ao que o estudante responde naturalmente; e é fecunda em questões práticas, interessantes e comuns.

A partir do exposto, constata-se o evidente reconhecimento do professor Joaquim de Oliveira Santos diante da sociedade maranhense. Por ocasião de seu óbito, o jornal Pacotilha reafirmou sua exímia trajetória do professor Joaquim no campo da educação, “[...] figura respeitável pelos seus belos atributos de inteligência e de caráter e pela grande soma de serviços prestados ao magistério maranhense, de que era um dos mais conspícuos membros" (PACOTILHA, 1930, p. 1).

$\mathrm{Na}$ somatória das contribuições do professor à educação maranhense, destacam-se várias tentativas de criação de jornais e revistas, dentre elas, a revista A Escola, criada em 1908 e dirigida por ele.

Antes de tal feito, Santos participou de quatro tentativas de produção de jornais e revistas com fins pedagógicos no Estado. Segundo Santos (1911), nenhuma das três logrou êxito, de acordo com a retomada histórica dessas experiências que ele faz na edição de lançamento da revista A Escola.

O professor Joaquim de Oliveira Santos afirma que a primeira tentativa ocorreu a partir do Decreto de 7 de março de 1900 e que o próprio Estado do Maranhão criou a referida revista pedagógica. Já a segunda tentativa foi idealizada por José Barroto Costa Rodrigues, oferecendo ao médico e professor Almir Parga Nina, e ao próprio Joaquim de Oliveira Santos, uma seção no jornal Pacotilha, para escreverem exclusivamente sobre assuntos pedagógicos.

$\mathrm{Na}$ tentativa seguinte, Almir Parga Nina juntamente com outros professores fundaram uma revista pedagógica, enquanto em maio de 1908, na quarta tentativa, Jerônimo Viveiros, Antônio Lopes da Cunha e Joaquim de Oliveira Santos, criaram a revista A Escola.

A revista A Escola se define como órgão de propaganda dos modernos métodos de ensino, com publicação bimestral, tendo como diretor Joaquim de Oliveira Santos, seu lema era "Fazer o que lhe for possível". O então diretor da revista era defensor ferrenho do ensino moderno $^{3}$, como indicam as aspirações e disputas presentes no cenário educacional brasileiro e relatadas na edição $\mathrm{n}^{\mathbf{0}} 1$ da referida revista.

Quando aparece uma ideia reformadora, formam-se dois grupos - um favorável e outro contrário a ela, sendo este ordinariamente o maior - o que é natural. Estabelece-

\footnotetext{
${ }^{3}$ Para Joaquim de Oliveira Santos, o ensino moderno deveria ser guiado pela ciência experimental, em que as práticas docentes não fossem pautadas na severidade com os alunos. Entre os materiais a serem ofertados às crianças, os livros e as tabuadas deveriam ser de agradáveis aspectos e com diversas figuras atraentes, a música, o desenho e a instrução cívica e moral fariam os alunos conhecerem os deveres a cumprirem com a família, a escola e a Pátria.
} 
se então a luta entre a ideia nova e a velha e não admira que a primeira seja vencida; mas é sempre para surgir adiante com mais elementos de resistência. [...] é o que se passa atualmente com o ensino moderno (SANTOS, 1909, p. 6).

Esse número da revista foi marcado por uma forte crítica ao ensino nos moldes tradicionais, na sessão intitulada $\mathrm{O}$ Ensino Moderno que questionava os recursos utilizados. Foi nesse contexto que Santos intitulou a tabuada de "irmã gêmea da carta de ABC", isso porque o material tratava o domínio dos números, seguindo a lógica dos demais materiais para a alfabetização, que assim como a cartilha de $\mathrm{ABC}$, não tinham atrativo, impossibilitando a criança de adquirir o gosto pela leitura, como podemos verificar na fala do diretor da revista:

[...] em lugar de uma tabuada nas condições daquela a que já nos referimos, - um livro atraente como o de leitura, onde se cultivam a observação e o raciocínio infantis, tornando assim os primeiros passos em número um poderoso meio de cultura mental da criança; e o cálculo, que a tanta gente boa enfastia e aprece tão inextricável; - uma das disciplinas mais agradáveis para o aluno e que pode ficar melhor conhecendo e, mais que qualquer outra, lhe prepara o espírito para fazer sem dificuldade estudo que vierem depois; em vez de uma escrita que começava no a e seguia invariavelmente a ordem alfabética, - a que principia na letra mais simples- i, e prossegue daí por diante, graduadas as dificuldades (SANTOS, 1909, p. 2).

De tal modo, como alternativa para o ensino moderno, são apresentadas propostas de mudanças nos procedimentos pedagógicos e nos materiais utilizados, com exaltação ao uso do livro didático e sugestões de modificações na tabuada. A seção intitulada "O Professor Normalista e o ensino" destaca que professor primário, além do desafio de implantar o método do ensino, precisa ainda enfrentar outras adversidades "[...] tem ainda a procurar práticas dos modernos métodos para as experimentar" (SANTOS, 1909, p. 3).

Assim, nas tentativas de contribuir com a modernização do ensino de matemática, o professor Santos enfatiza a necessidade de diferentes metodologias e recursos. Ainda nas reflexões pela modernização do ensino, ele defende um moderno ensino para o cálculo, definindo-o como de fácil aprendizagem, a depender das metodologias utilizadas (SANTOS, 1909).

O professor Joaquim de Oliveira Santos desempenhou funções como docente, para além da sala de aula, exercendo também funções técnicas conforme escreveu em carta: “[...] em 1909, ano em que fui desligado da Escola para desempenhar a comissão de que ainda estou incumbido, [...] duma lei estadual)” (DIÁRIO DO MARANHÃO, 1911, p. 1).

$\mathrm{O}$ encargo ao qual se referia era o convite feito pelo Estado para integrar a equipe que organizou a reforma da Instrução Pública para o Maranhão no final do governo de Urbano Santos, em 1922, posta em prática pelo Decreto n ${ }^{\circ} 616$ de 15 de fevereiro de 1923, na mensagem ao Congresso em 1922, o nome do professor aparece como membro da comissão "[...] o projeto de reforma, confiado a competência dos drs. Godofredo Mendes Vianna e Cesario Veras e professores Joaquim de Oliveira Santos [...]” (MARANHÃO, 1922, p. 38).

No âmbito da escrita de livros e também em parceria com Almir Parga Nina, Joaquim de Oliveira Santos tem uma extensa lista de obras. ${ }^{4}$

Durante o governo de Benedito Pereira Leite, foi sancionada Lei $\mathrm{n}^{\circ} .475$ de 21 de março de 1908, autorizando o governo do Maranhão a imprimir duas obras didáticas escritas por

\footnotetext{
${ }^{4}$ Meu Primeiro livro de cálculos; Taboada Indutiva; Moderna Tabuada ou Primeiros Exercícios de Ginástica com os números; Elementos de Aritmética em séries indutivas; Aritmética graduada para a escola primária (uma série para cada ano escolar); Exercícios de linguagem escrita (série de 5 volumes, uma para cada ano escolar).
} 
Joaquim de Oliveira Santos, em parceria com Almir Parga Nina, a serem utilizadas na escola primária maranhense: Aritmética graduada e Exercícios de Composição.

$\mathrm{Na}$ Lei, o Estado se responsabiliza pelos recursos para impressão de mil exemplares das obras. Destas, 500 unidades seriam entregues nas escolas maranhenses e a outra metade para a viúva de Almir Parga Nina. No Artigo $2^{\circ}$ da Lei, o Estado fica responsável pelo pagamento do trabalho do professor, "o governo comissionará o professor da Escola Normal Joaquim de Oliveira Santos, com seus vencimentos integrais, para completar e rever estes trabalhos e superintender lhes a impressão" (LEI No . 475, 21/03/1908).

Naquele mesmo ano, outros títulos de autoria de Joaquim de Oliveira Santos, em parceria com Almir Parga Nina, foram adotados na Instrução Primária maranhense, conforme noticiou a imprensa, o livro "Moderna Tabuada ou Primeiros Exercícios de Ginástica com os números são 97 lições com as quatros operações, trabalho foi mandado imprimir pelo Estado: São proprietários da obra a Exmª viúva d'aquele clínico e o professor Santos." (DIÁRIO DO MARANHÃO, 1908, p. 1).

Em 1909 foi publicado o segundo número da Taboada Indutiva ${ }^{5}$, as impressões foram custeadas pelo Estado com 148 lições relacionadas com operações elementares. Nessa obra, Santos apresenta orientações didáticas para os professores do ensino primário, algumas das lições eram compostas de problemas "gradativamente ordenados".

Destarte, suas obras eram direcionadas para o ensino primário e para séries posteriores: Aritmética elementar em séries indutivas, Exercícios de linguagem escrita (série de 6 volumes, uma para cada ano escolar), em parceria com Almir Nina, e Aritmética graduada para a escola primária (uma série para cada ano escolar) (PACOTILHA, 1930).

A coleção intitulada Aritmética Graduada para Escola Primária tornou-se referência na Instrução Pública maranhense. Dos seis volumes, conseguimos localizar dois, do $3^{\circ}$ e $5^{\circ}$ ano, como podemos observar nas Figuras 3 e 4.

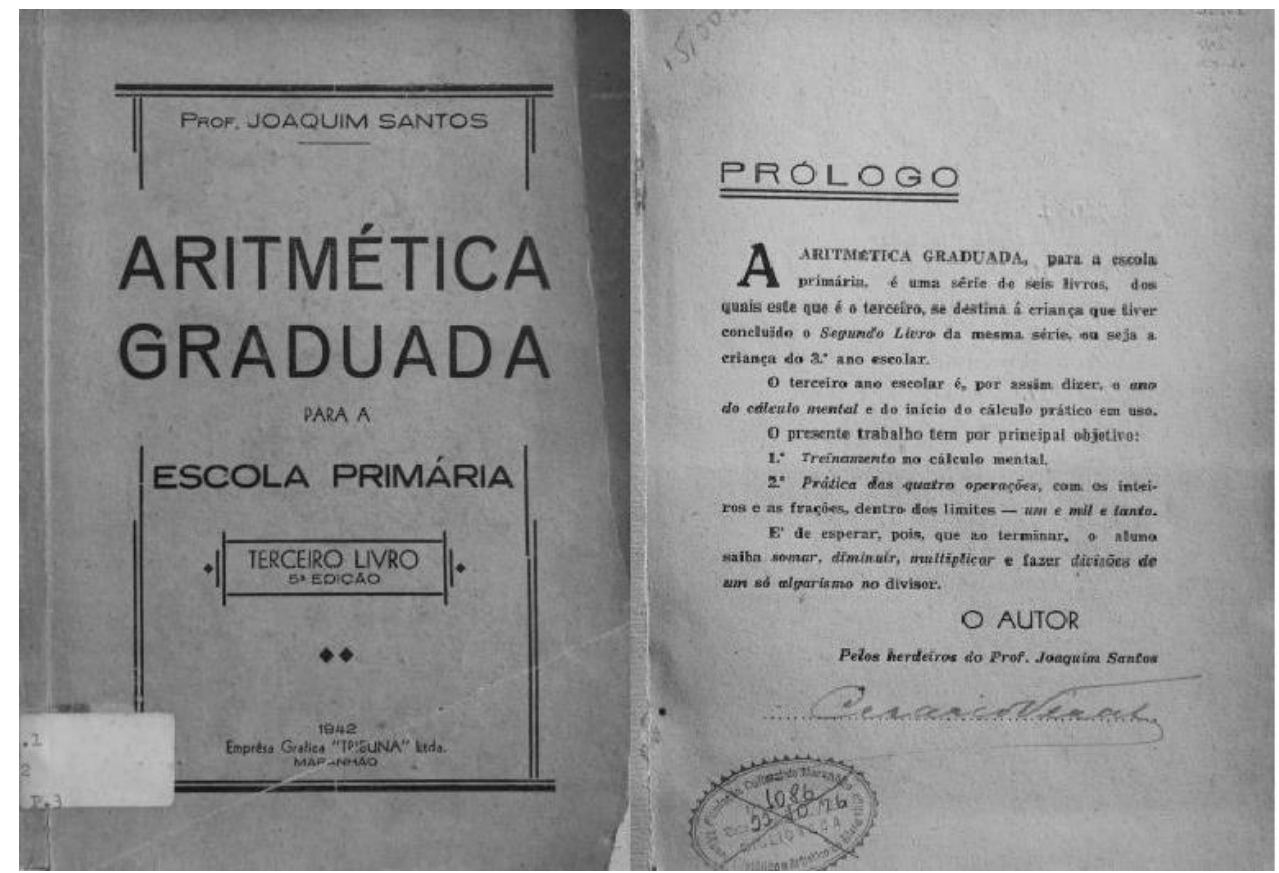

Figura 3 - Capa e prólogo do livro de matemática do $3^{\circ}$ ano

Fonte: Biblioteca do Museu Histórico e Artístico do Maranhão

\footnotetext{
${ }^{5}$ Ipsis litteris.
} 


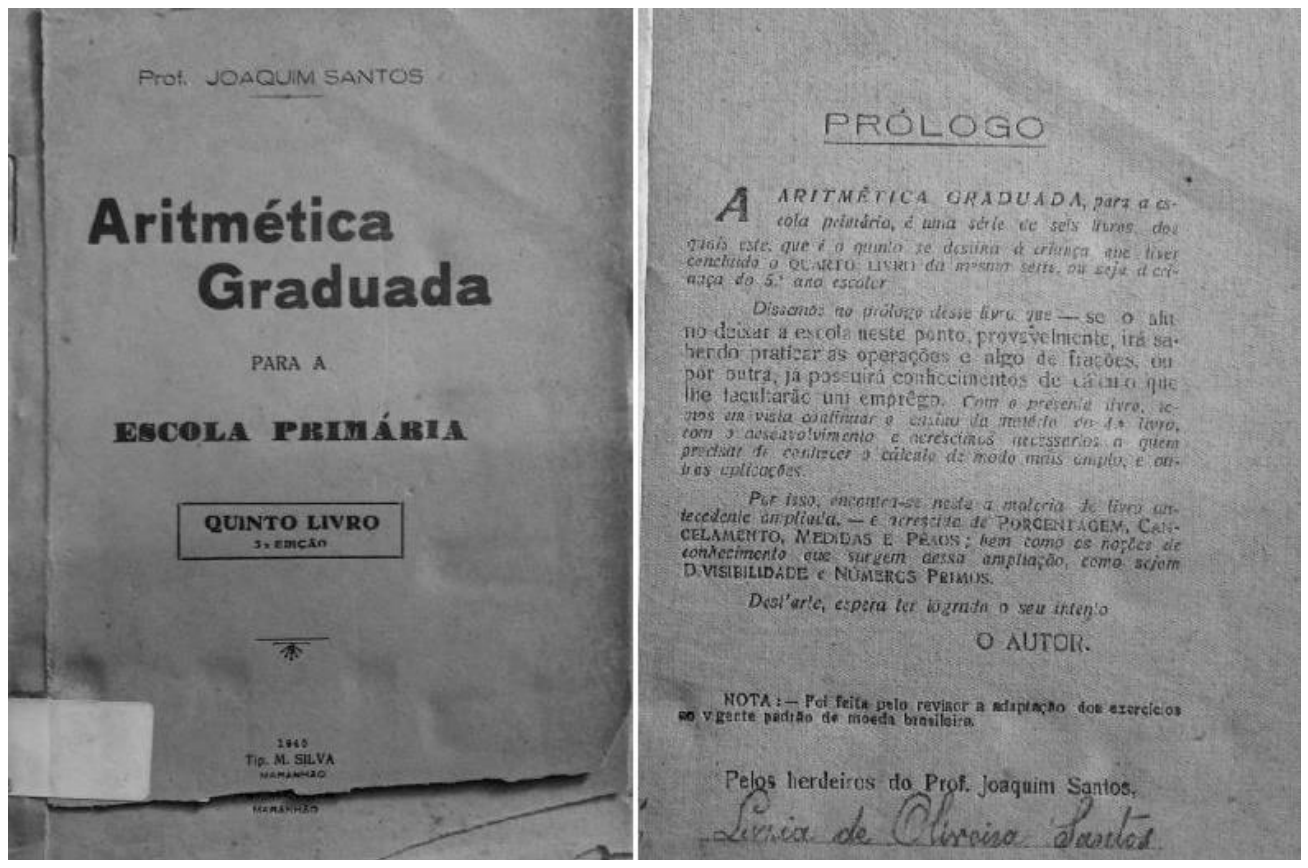

Figura 4 - Capa e prólogo do livro de matemática do $5^{\circ}$ ano Fonte: Biblioteca do Museu Histórico e Artístico do Maranhão

O professor Joaquim de Oliveira Santos deixa claro os objetivos de cada livro. No prólogo, ele define o terceiro ano, como o ano do cálculo mental e do início do cálculo prático em uso. O objetivo do livro para esse ano é treinar o cálculo mental e prática das quatro operações, com números inteiros e frações, dentro dos limites - um e mil e tanto - a ideia é que ao final do terceiro ano o aluno saiba somar, diminuir, multiplicar e fazer divisões de um só algarismo no divisor.

Para o $5^{\circ}$ ano, a obra contempla porcentagem, cancelamento, medidas e pesos, divisibilidade e números primos, os objetivos são continuar com os conteúdos do $4^{\circ}$ ano, com os acréscimos necessários, além de conhecer o cálculo de modo mais amplo, e outras aplicações. Os exemplares encontrados já são $5^{a}$ e $3^{a}$ edição, respectivamente, já com notas realizadas pelos herdeiros de Joaquim Santos.

Ao publicar Elementos de aritmética em séries indutivas, em 1911, no prólogo ele escreve: "este livro é destinado a todos quando, tendo concluído o curso de instrução primária, passaram a estudar o primeiro ano de aritmética elementar seja qual for a carreira que tenham em vista seguir" (SANTOS, 1911, não paginado).

Considerando essas assertivas, Pinto (2017) afirma que o método intuitivo predominou no ensino primário desde o final do século XIX, o que consolida nossa hipótese de que os saberes defendidos por Joaquim de Oliveira Santos estavam em consonância com as propostas vigentes no Brasil. Assim, como é próprio do campo educacional, o educador maranhense enfrentou conflitos, pois seus livros Primeiro Livro de Cálculos e Tabuada Indutiva, impressos pelo Estado, foram adotados pela Instrução Pública do Maranhão para todas as escolas de ensino primário, enfrentou desafios para ter suas obras adotadas na Escola Modelo Benedito Leite.

A Escola Modelo era o Colégio de Aplicação da Escola Normal. O diretor da Escola Modelo e da Escola Normal era o mesmo, no período dos conflitos para adoção dos livros de Joaquim de Oliveira Santos, ocupava o cargo Barbosa de Godói. A Escola Modelo Benedito 
Leite, foi tida na primeira metade do século XX como a mais importante instituição de ensino primário maranhense.

Em artigo publicado no jornal, no dia 05 de junho, do ano de 1911, Joaquim de Oliveira Santos, a convite de Antônio Lobo, responsável pela Instrução Pública maranhense, publica uma carta respondendo a Barbosa de Godóis, pela recusa em adotar seus livros na Escola Modelo.

Na carta, o professor Joaquim argumenta sobre seus livros, escritos em parceria com Almir Parga Nina:

\begin{abstract}
A vossa recusa à adoção dos meus ditos livrinhos na Escola modelo Benedito Leite, é uma contestação implícita ao que afirmo nas Duas Palavras de que faço preencher as lições do Primeiro Livro de Cálculos: estar ele em condições de usados em toda e qualquer escola primária para o início do ensino de cálculo; e, uma vez que ele não convenha ao ensino de cálculo na Escola Modelo, não pode, isso fato, convir ao mesmo ensino nas demais escolas, por isso mesmo que ela deve ser o modelo para todas as outras (DIÁRIO DO MARANHÃO, 6 jun. 1911, p. 1).
\end{abstract}

Joaquim de Oliveira Santos faz essa afirmação porque a obra já era adotada pela Instrução Pública para todo ensino primário do Maranhão, então como aquela que deveria ser a escola Modelo para todas as outras não utilizaria o seu livro? Diante disso, no dia 06 de junho, Antônio Lobo escreve um artigo no mesmo jornal e emite um parecer afirmando que tendo a Escola o seu programa e processo de ensino estabelecido pelo governo, não é possível abrir mão da adoção dos dois livros, visto que conhece o mérito do trabalho do seu autor, e que as obras podem auxiliar os professores na adaptação de métodos de ensino (DIÁRIO DO MARANHÃO, 1911, p. 1).

A ênfase dada às contribuições da obra para o ensino de matemática ocorre porque Joaquim Santos já se consolidava como um defensor da formação de professores primários para lidar com o ensino moderno. Assim, toda disputa pela adoção ou não dos livros de Joaquim de Oliveira Santos evidenciam que o campo da educação é, sobretudo, uma arena de disputas e é sobre esses jogos de poderes que são escolhidos os saberes a serem, ou não ensinados; logo, os conflitos são inerentes às instâncias que cooperam de diferentes maneiras para deliberar sobre esses saberes, ponderando a profissão de professor e as associações/sindicatos que a representa (VALENTE, 2017).

\title{
Considerações finais
}

A produção do professor Joaquim de Oliveira Santos, identificada nos documentos aos quais tivemos acesso, evidencia a incessante busca do professor pela modernização da Aritmética da escola primária ludovicense, bem como por uma melhor qualidade da formação de professores para a instrução primária maranhense em tempos da vaga intuitiva.

Isto porque, ele manteve uma ávida preocupação em tornar o ensino da Aritmética acessível a todos, com inclusão de textos nos problemas matemáticos, assertiva que ele mesmo explica nos seus escritos; ao mesmo tempo manteve diálogo com publicações sobre Aritmética, Álgebra, e Geometria de nível internacional, ao utilizar elementos dessas obras nas suas aulas na formação de professores, Joaquim de Oliveira Santos contribuiu para a modernização na Escola Primária e na formação dos professores que ensinavam matemática à época.

Concluímos que o professor Joaquim de Oliveira Santos desenvolveu trabalhos com vistas a essa modernização em São Luís, em harmonia com as produções em circulação nos cenários educacionais em níveis nacional e internacional, daí a nossa opção pelo conceito de "glocal", ancorada em Roger Chartier. 
Os emaranhados das notícias, veiculadas nos jornais e documentos oficiais, confirmam a rica trajetória do professor Joaquim Oliveira dos Santos, e suas inciativas para a modernização da Aritmética do ensino na Escola Primária ludovicense.

Ademais, os embates com o diretor da Escola Normal pela adoção de livros estrangeiros, de Geometria e Álgebra, enquanto a Escola Modelo enfrentou conflitos até a efetivação do uso de livros de Aritmética de sua autoria, mostram que Joaquim atuava principalmente em duas frentes com vistas a modernização do ensino de matemática: a formação de professores e o ensino de aritmética.

Perante a sociedade maranhense, esse reconhecimento ficou mais evidente quando, em 1947, foi criada a cooperativa de ensino Joaquim de Oliveira Santos, e seus livros foram adotados no Instituto de Educação. Até a década de 1950, as edições posteriores à sua morte passaram a ser de responsabilidade de sua família.

\section{Referências}

CASTRO, C. A. Arquivos e fontes na história da educação. In: GONDRA. J. G; MACHADO. M. C. G; SIMÕES. R. H. S. (Orgs.) História da Educação, Matrizes interpretativas e internacionalização. Vitória: EDUFES, 2017.

CHARTIER, R. "Cultura popular”: revisando um conceito historiográfico. Estudos Históricos, Rio de Janeiro, v. 8, n. 16, p. 179-192, 1995.

CHARTIER, R. A história ou a leitura do tempo. 2. ed. Tradução de Cristina Antunes. Belo Horizonte: Autêntica Editora, 2017.

DE CERTEAU, M. A escrita da história. Rio de Janeiro: Forense universitária, 1982.

PINTO, N. B. Matrizes teóricas dos saberes elementares matemáticos da escola primária em tempos de primeira república. Revista Diálogo Educacional, Curitiba, v. 17, n. 51, p. 185-205, jan./mar. 2017.

VALENTE, W. R. A matemática a ensinar e a matemática para ensinar. In: HOFSTETTER, R.; VALENTE, W. R. (Orgs.) Saberes em (trans)formação: tema central da formação de professores. São Paulo: Editora Livraria da Física, 2017.

\section{Fontes consultadas}

A ESCOLA: Orgam de propaganda dos modernos métodos de ensino, São Luís, ano 1, n. 1, 9 de outubro de $1909 . \quad$ Disponível em: <http://casas.cultura.ma.gov.br/portal/sgc/modulos/sgc_bpbl/acervo_digital/arq_ad/20150625 110228.pdf>. Acesso em: 31 mar. 2020.

DIÁRIO DO MARANHÃO: jornal do commercio, lavoura e indústria. São Luís, ano 39, n. 10337, p. 1, 23 de maio de 1908. 4 p. Disponível em: $<$ http://memoria.bn.br/DocReader/docreader.aspx?bib=720011\&pesq=>. Acesso em: 30 mar. 2020.

DIÁRIO DO MARANHÃO: orgão imparcial. São Luís, ano 42, n. 11386, p. 1, 5 de junho de 1911. 4 p. Disponível em: <http://memoria.bn.br/DocReader/doc reader.aspx?bib= 720011\&pesq=>. Acesso em: 30 mar. 2020. 
DIÁRIO DO MARANHÃ̃: orgão imparcial. São Luís, ano 42, n. 11387, p. 1, 6 de junho de 1911. 4 p. Disponível em: <http://memoria.bn.br/DocReader/docreader.aspx?bib=720011\&pesq=>. Acesso em: 30 mar. 2020.

MARANHÃO. Decreto n ${ }^{\circ}$ 616, de 15 de fevereiro de 1923. Approva o regulamento para os estabelecimentos de instrução pública do Estado. Collecção de leis e decretos do Estado do Maranhão do anno de 1922. São Luís: Imprensa Official, 1923. Disponível em: <http://casas.cultura.ma.gov.br/portal/sgc/modulos/sgc_bpbl/acervo_digital/arq_ad/20141118 114305.pdf>. Acesso em: 30 mar. 2020.

MARANHÃO. Lei n. 475 de 21 de março de 1908. Auctorisa o Governo a mandar imprimir duas obras didacticas do Dr. Almir Parga Nina e professor Joaquim de Oliveira Santos. Colecção das Leis, Pareceres, Resoluções do Congresso, Decretos e Decisões do Estado do Maranhão de 1908. Maranhão: Typ. da Imprensa Official, 1909. Disponível em: <http://casas.cultura.ma.gov.br/portal/sgc/modulos/sgc_bpbl/acervo_digital/arq_ad/20141118 112308.pdf>. Acesso em: 30 mar. 2020.

MARANHÃO. Lei n. 611 de 11 de abril de 1912. Auctoriza o Governo a entregar á viuva do dr. Almir Parga Nina e ao professor Joaquim de Oliveira Santos a quantia de que trata o art. 1. da lei n. 475, de 21 de março de 1908. Leis do Estado, 1912. Maranhão: Typ. da Imprensa Official, $1912 . \quad$ Disponível em: <http://casas.cultura.ma.gov.br/portal/sgc/modulos/sgc_bpbl/ acervo_digital/arq_ad/20141118112308.pdf>. Acesso em: 30 mar. 2020.

MARANHÃO. Mensagem apresentada ao Congresso do Estado Maranhão na 1. ${ }^{a}$ sessão da 11. ${ }^{a}$ Legislatura, em 5 de Fevereiro de 1922 pelo Exm. Sr. Dr. Urbano Santos da Costa Araujo, presidente do Estado. Maranhão: Imp. Official, 1922. Disponível em: $<\mathrm{http}: / /$ ddsnext.crl.edu/titles/169?terms $=1922 \&$ item_id $=3607 \# ? \mathrm{~h}=1922 \& \mathrm{c}=0 \& \mathrm{~m}=156 \& \mathrm{~s}=0$ \& $\mathrm{cv}=1 \& \mathrm{r}=0 \& \mathrm{xywh}=-1343 \% 2 \mathrm{C} 1 \% 2 \mathrm{C} 4381 \% 2 \mathrm{C} 3$ 091>. Acesso em: 30 mar. 2020.

PACOTILHA: jornal da tarde. São Luís, ano 20, n. 17, p. 1, 17 de janeiro de 1900. 4 p. Disponível em: <http://memoria.bn.br/DocReader/docmulti.aspx?bib=168319\&pesq=>. Acesso em: 30 mar. 2020.

PACOTILHA: jornal da tarde. São Luís, ano 28, n. 40, p. 1, 17 de fevereiro de 1908. 4 p. Disponível em: <http://memoria.bn.br/DocReader/docmulti.aspx?bib=168319\&pesq=>. Acesso em: 30 mar. 2020.

PACOTILHA: jornal da tarde. São Luís, ano 49, p. 1, 24 de setembro de 1930. 4 p. Disponível em: <http://memoria.bn.br/DocReader/docmulti.aspx?bib=168319\&pesq=>. Acesso em: 30 mar. 2020.

SANTOS, J. Elementos de Aritmetica em séries indutivas. 1. ed. São Luís: Diário do Maranhão, $1911 . \quad$ Disponível em: <http://casas.cultura.ma.gov.br/portal/sgc/modulos/sgc_bpbl/acervo_digital/arq_ad/20170102 115156.pdf>. Acesso em: 30 mar. 2020. 